\title{
BMJ Open Housing situation and healthcare for patients in a psychiatric centre in Berlin, Germany: a cross-sectional patient survey
} \begin{tabular}{l}
\hline Stefanie Schreiter D , ${ }^{1}$ Sascha Heidrich, ${ }^{1}$ Jamie $Z$ Zulauf, ${ }^{1}$ Ute Saathoff, ${ }^{1}$ \\
Anne Brückner, ${ }^{1}$ Tomislav Majic, ${ }^{1,2}$ Wulf Rössler, ${ }^{1,3}$ Meryam Schouler-Ocak, ${ }^{1,2}$ \\
Michael R Krausz, ${ }^{4}$ Felix Bermpohl, ${ }^{1,2}$ Josef Bäuml, ${ }^{5}$ Stefan Gutwinski ${ }^{1,2}$
\end{tabular}

To cite: Schreiter S, Heidrich S, Zulauf $\mathrm{J}$, et al. Housing situation and healthcare for patients in a psychiatric centre in Berlin, Germany: a cross-sectional patient survey. BMJ Open 2019;9:e032576. doi:10.1136/ bmjopen-2019-032576

- Prepublication history and additional material for this paper are available online. To view these files, please visit the journal online (http://dx.doi org/10.1136/bmjopen-2019032576).

Received 25 June 2019 Revised 18 November 2019 Accepted 19 November 2019

Check for updates

(C) Author(s) (or their employer(s)) 2019. Re-use permitted under CC BY-NC. No commercial re-use. See rights and permissions. Published by BMJ.

For numbered affiliations see end of article.

Correspondence to Dr Stefanie Schreiter; stefanie.schreiter@charite.de

\section{ABSTRACT}

Objective To determine the housing situation among people seeking psychiatric treatment in relation to morbidity and service utilisation.

Design Cross-sectional patient survey.

Setting Psychiatric centre with a defined catchment area in Berlin, Germany, March-September 2016.

Participants 540 psychiatric inpatients including day clinics $(43.2 \%$ of all admitted patients in the study period $(n=1251))$.

Main outcome measures Housing status 30 days prior the interview as well as influencing variables including service use, psychiatric morbidity and sociodemographic variables.

Results In our survey, 327 participants $(68.7 \%)$ currently rented or owned an own apartment; 62 (13.0\%) reported to be homeless (living on the street or in shelters for homeless or refugees); 87 (18.3\%) were accommodated in sociotherapeutic facilities. Participants without an own apartment were more likely to be male and younger and to have a lower level of education. Homeless participants were diagnosed with a substance use disorder significantly more often (74.2\%). Psychotic disorders were the highest among homeless participants (29.0\%). Concerning service use, we did neither find a lower utilisation of ambulatory services nor a higher utilisation of hospital-based care among homeless participants.

Conclusions Our findings underline the need for effective housing for people with mental illness. Despite many sociotherapeutic facilities, a concerning number of people with mental illness is living in homelessness. Especially early interventions addressing substance use might prevent future homelessness.

\section{INTRODUCTION}

Since the early 20th century, social determinants of health were an important part of psychiatric research. ${ }^{1}$ Today, we know that mental illness and marginalised, instable housing are often closely connected. But research on suitable housing forms for people with severe mental illness is scarce. ${ }^{2}$ A cross-sectional survey among 1000 people
Strengths and limitations of this study

- This study is the largest German study on housing situation among people in acute psychiatric care

- The study was carried out in a district which characterises many housing problems of larger cities in western countries, with partially low living standards and relatively high rates of migrants.

- Our approach focussed on homeless populations or hospital-based medical records, and on structured interviews with people in acute psychiatric care.

- Regarding limitations, our data cannot be generalised for other districts especially rural areas, since studies have shown that the risk for serious mental illness is generally higher in cities compared with rural areas.

- We conducted our interviews during summer time, which might have changed the ratio of homeless patients in our clinic.

in outpatient treatment in five different US cities reported a high variety in housing. ${ }^{3}$ Between one-third and one-half of individuals surveyed reported they had been living in specialised housing for people with mental disorders at some point in their lives and one-fifth currently living in such housing. ${ }^{3}$ Between $1 \%$ and $5.2 \%$ were homeless or lived in shelters. ${ }^{3}$ The relatively low prevalence of homelessness among people in outpatient treatment in this US study could be a result of the US healthcare system, which less often reaches homeless people with mental illness. In regard to causal factors, besides poor physical and mental health and substance use, homelessness is a complex phenomenon: childhood trauma, ${ }^{2}$ unfavourable structural conditions like a shortage of affordable housing, poverty and unemployment as well as difficulties with housing-related services, health services and education have 
been discussed to be key factors. An inadequate housing situation for people with severe mental illness and especially homelessness are associated with poorer prognosis, increased mortality ${ }^{3}$ due to higher rates of suicides, ${ }^{4-6}$ substance use $^{7}$ and somatic conditions like infectious diseases or respiratory illness ${ }^{8-11}$ and higher rates of criminality, ${ }^{12-14}$ violence ${ }^{15-17}$ and neurocognitive impairment. ${ }^{18}$

Surveys conducted in the US found that there was no city or county in which a person with a mental disorder living solely on disability benefits could afford the fair market rent for a modest efficiency apartment. ${ }^{19} 20$ Increasing rents and missing welfare housing especially in urban areas like Berlin have led to increasing numbers of homeless people in Germany, ${ }^{21}$ of which $77.5 \%$ suffer from a mental illness. ${ }^{22}$ Germany, in contrast to the US, has a universal healthcare system paid for by a combination of statutory health insurance and a small sector of private health insurance. Health insurance is compulsory for the whole population (irrespective of people from other European states or illegal immigrants). They are obligated to provide a broad benefit package and cannot refuse membership or otherwise discriminate on a health risk profile of potential applicants. Social welfare beneficiaries are also enrolled in statutory health insurance, and municipalities pay contributions on behalf of them. Additionally, the social service system includes different forms of specialised housing services, case management and drug counselling services. There are three types of specialised housing for people with mental illness in Germany (ambulatory and 'inpatient' assisted housing as well as assisted housing in families) each of them including a broad variety of housing settings and assistance funded by social welfare. ${ }^{23}$ Additionally, there are different forms of housing for homeless people like shelters differing in their barriers of, for example, drug and alcohol use and level of additional assistance as well as refugee shelters and women shelters.

The literature on healthcare system use among homeless people is small and mainly from North America and the UK. ${ }^{24-26}$ These studies predominantly show low utilisation of primary care and an almost exclusive use of emergency care or hospital-based care due to more severe and complex health conditions. ${ }^{27}$ Recent studies from Canada suggest that heavy use of emergency care is mainly associated with a small group of 'high users' among homeless people. ${ }^{25}$ These patterns of healthcare use seem to be especially determined by the respective healthcare system. ${ }^{28-30}$ Salit et al analysed hospital-discharge data of 18864 admissions of homeless adults to New York City's public general hospitals and found in $80.6 \%$ a diagnosis of substance abuse or mental illness and a $36 \%$ longer duration of treatment compared with non-homeless patients. $^{31}$

German studies among homeless populations evaluating service use are scarce and were mostly conducted in the 1990s. They consist of mainly small samples and document a high number of unmet needs especially for mental health problems. ${ }^{32-34}$ The largest and most recent
German study conducted in Munich from 2010 to 2012 estimated annual rates of medical service use among homeless people between $20 \%$ and $50 \% .^{35}$ Authors report that in $75 \%$ a psychiatric inpatient treatment exceeded the onset of homelessness ${ }^{35}$ indicating that housing needs to be included in the psychiatric treatment setting.

There are only few studies on housing of people in psychiatric treatment: Wessel et al found $31 \%$ of psychiatric inpatients in the German city Mannheim to be without a private home in a study from 1993 to $1994 .^{36}$ A study from Copenhagen from 1992 reported in 22\% of 1581 people in psychiatric treatment serious housing problems. ${ }^{37}$ Considering the fast-changing social challenges of Western societies, these data cannot be considered representative for the present situation.

Given the significance of housing for the organisation of services, we conducted a cross-sectional patient survey ('WOHIN-Studie' Wohnungsnot bei Menschen mit seelischen Erkrankungen) among users of psychiatric inpatient or day clinic care in one of the largest psychiatric hospitals in the centre of Berlin with a defined catchment area in an underprivileged district with approximately 270000 inhabitants. ${ }^{38} 39$ The goal was a comprehensive description of housing stability and related healthcare use patterns as well as associated factors with poorer housing stability. We hypothesised a longer length of stay (LoS) and a higher rate of readmissions among participants with a more instable housing status as well as a poorer use of social services.

\section{METHODS}

\section{Study design and participants}

We performed a cross-sectional patient survey of all inpatients including day clinics (inpatient treatment without overnight stay) treated in the catchment area of the Psychiatric University Hospital Charité at St. Hedwig Hospital over a 6-month period (15 March-15 September 2016). People in outpatient treatment were not included. The hospital provides psychiatric treatment for all inhabitants living in the catchment area of the districts Wedding, Tiergarten und Moabit of the City of Berlin. These districts have relatively low living standards and high rates of migrants especially from other European countries. Number of inhabitants in these districts on 31 December 2014 was 268239 (7.53\% of the total number of Berlin's 3562166 inhabitants). ${ }^{40}$

The hospital offers inpatient treatment for 192 people spread out on three general psychiatric wards and four specialised wards (addiction, depression, gerontopsychiatry, 'Soteria' (treatment of people with early psychosis)) as well as 5 day clinics. In the study period, a total number of 1251 people were admitted (excluding outpatients and readmissions), which equates to a hospital frequency of 93.3 per 10000 inhabitants per year (hospital frequency for psychiatric admissions in Berlin 2015: 108.3 per 10000 inhabitants ${ }^{41}$ ). 
Trained interviewers approached participants as soon as possible after admission, taking into account their mental health state as well as their ability to consent. All participants gave written informed consent before participation. A monetary incentive $(5 €)$ was offered for participation. Interviews lasted on average 1 hour. We conducted 11 interviews $(2 \%)$ with a professional interpreter.

The whole study sample consists of 1251 participants. 540 subjects $(43.2 \%)$ were willing to participate in the interview. 328 people $(26.2 \%)$ rejected to participate and 383 subjects $(30.6 \%)$ could not be reached (short LoS, inability to consent or premature discharge).

In order to calculate representativeness of participants, the following parameters were extracted for nonparticipating patients from hospital records: age, gender, diagnoses, date of admission and discharge, compulsory admission or treatment.

Participants were significantly more likely to be male $\left(\mathrm{X}^{2}=4.34 ; \mathrm{p}=0.037\right)$, which might be explained by the large number of participants with substance use disorders recruited from our ward for addiction. Thus, substance use disorders (International Classification of Diseases, ICD-10:F10-F19) were significantly more often diagnosed among participants (52.22\% vs $42.05 \%, \mathrm{X}^{2}=12.76$; $\left.\mathrm{p}<0.001\right)$. Participants with substance use disorders might have had a higher motivation due to the monetary incentive and were more likely to be able to consent. Furthermore, non-participants were significantly older than participants $(\mathrm{T}=-2.96, \mathrm{p}=0.003)$, which can be explained by the number of people with gerontopsychiatric disorders, which were often not able to consent due to organic mental disorders. Accordingly, organic mental disorders (ICD-10:F00-F09) were significantly more likely to be diagnosed among nonparticipating patients $\left(4.26 \%\right.$ vs $\left.9.99 \%, \mathrm{X}^{2}=14.48 ; \mathrm{p}<0.001\right)$. Personality disorders (ICD-10:F60-F69) were significantly more likely to be found among participants (20.37\% vs $11.53 \%, \mathrm{X}^{2}=18.45 ; \mathrm{p}<0.001$ ), possibly due to their ability to consent. Non-participants showed a significantly shorter LoS (median: 10 vs 28 days, $\mathrm{U}=107451.50, \mathrm{p}<0.000$ ), which results from factors like premature discharge, short detoxification, and so on, so patients could not be reached by study personnel. Moreover, non-participants were significantly more often admitted on a compulsory basis $(15.61 \%$ vs $8.52 \%, \mathrm{X}^{2}=13.93 ; \mathrm{p}=0.001$ ), which evidently reduced their motivation and ability to consent. Participants and non-participants did not differ significantly regarding compulsory hospitalisation $\left(\mathrm{X}^{2}=1.95 ; \mathrm{p}=0.0583\right)$, distribution of schizophrenia, schizotypal and delusional disorders (ICD-10:F20-29, $\mathrm{X}^{2}=2.99 ; \mathrm{p}=0.084$ ), affective disorders (ICD-10:F30-39, $\mathrm{X}^{2}=2.01 ; \mathrm{p}=0.151$ ) and neurotic, stressrelated and somatoform disorders (ICD10:F40-49, $\mathrm{X}^{2}=1.13$; $\mathrm{p}=0.288$ ).

\section{Patient and public involvement}

The interview had been evaluated before study start by 10 patients regarding comprehensibility and fitting of outcome measures to patient's experience and priorities.
Results will be disseminated to participants through presentation on patient involved conferences.

\section{Instruments}

Sociodemographic variables, housing status, service use among other sociodemographic variables were covered by the structured interview. Diagnoses of mental disorders were based on discharge records and provided by psychiatric clinicians based on ICD-10 criteria. ${ }^{42}$ Verbal intelligence was approximated using the Multiple Choice Vocabulary Test. ${ }^{43}$ Symptom severity of participants with a psychotic disorder was assessed using the Positive and Negative Syndrome Scale. ${ }^{44}$ The service use was studied in terms of use of ambulatory mental health services mostly financed through the social service code, but also services offered for homeless people in the city as well as hospitalrelated variables ( $\mathrm{LoS}$ and rate of readmissions).

The housing status was categorised based on the predominant housing situation 30 days prior to admission. Housing status was clustered into three groups: (1) homeless participant group (HPG, including literally homeless, emergency shelter, homeless shelter, women's refuge, refugee shelter, improvised accommodation); (2) apartment participant group (APG, including rented apartment, residential property); and (3) sociotherapeutic facilities participant group (SPG, including therapeutic shared apartment, assisted accommodation, special-care home; detailed information on distribution of housing status in figures 1 and 2). In order to minimise the self-report-bias, interviewers checked given information with social workers and documented information on housing in the clinic's electronic health record.

\section{Statistical analysis}

Statistical analyses were performed with SPSS V.19. ${ }^{45}$ Standard descriptive analyses with the corresponding statistical parameters (means, SD) were calculated depending on the data material. In the event of corresponding frequency distributions, $\chi^{2}$ tests were used to analyse differences. As the parameter, Pearson's $\chi^{2}$ value was checked for significance. Normal distribution was checked with the ShapiroWilk test. In case of normal distribution and interval scale level, analysis of variance was performed with adjusting for multiple comparisons by using Scheffe's method. If preconditions were not fulfilled, Kruskal-Wallis test and if significant, Mann-Whitney test were used with adjusting for multiple comparisons by using Bonferroni's method.

A multivariable binary logistic regression was performed to explore the association between sociodemographic and clinical predictors for being readmitted 6 months prior to the interview. Multiple linear regression analysis was used to test the extent to which sociodemographic variables, clinical variables and residential status were associated with logarithm of LoS. LoS was transformed into natural logarithm since variables were not normally distributed (in case of zero, we added the value of one before the transformation). Independent variables were entered into the model through sequential steps to allow the assessment of 


\section{1,251 Participants}

01.03.-30.09.2016
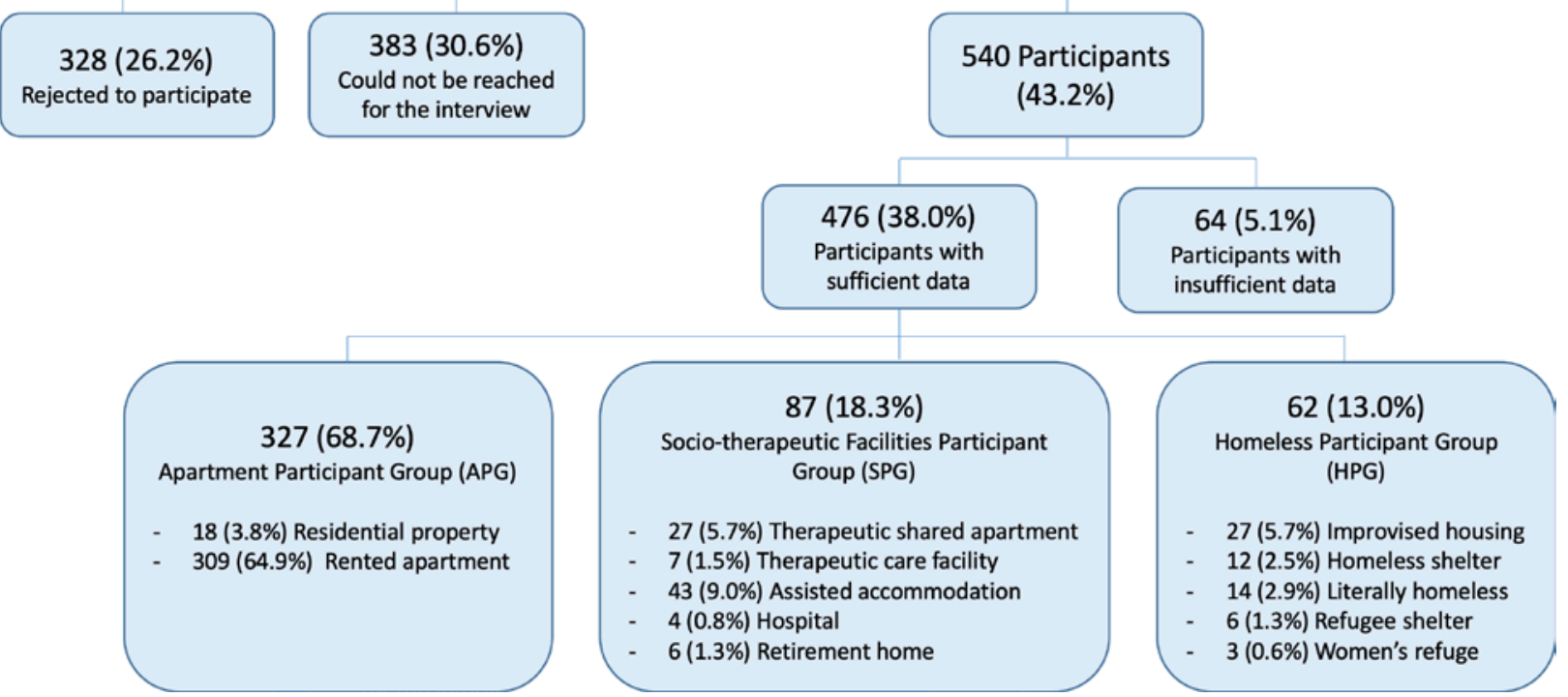

Figure 1 Flow chart of clustering process of housing status of participants.

incremental contributions of each step to the explained variance (based on corrected $\mathrm{R}^{2}$ ). Blocks of independent variables and their order of entry in the multiple regression analysis were based on a priori assumptions. Age and gender were entered in the first step. Clinical indicators of psychiatric diagnosis based on ICD-10 criteria were entered in the second step. The final step included housing status (HPG, SPG in reference to APG) to examine whether this variable accounted for additional variance, having controlled for all the variables entered in the previous steps. A multinomial logistic regression analysis was used to estimate the association between residential status and sociodemographic as well as clinical variables. We performed subgroup analyses for diagnostic subgroups with sufficient sample size. Authors followed strobe reporting guidelines.

\section{RESULTS}

\section{Housing conditions}

In our survey, 540 person participated in the interview. Sixty-four were not included in further analysis due to insufficient data on housing stability (especially difficulty to classify, for example, many changes of housing situation or participants staying with family or friends which could not be categorised as homeless or own apartment; a closer description of excluded participants can be found in online supplementary Stable 1). Detailed information of housing type for the 476 remaining participants can be found in figures 1 and 2. The distribution of housing groups among inpatients (excluding day-clinic patients) was $60.9 \%$ in $\mathrm{APG}, 21.1 \%$ in SPG and $18.0 \%$ in HPG $(\mathrm{n}=322)$.

\section{Sociodemographic background and distribution of disorder- related variables}

Comparing the three housing groups revealed significant group differences in gender and age, with the HPG being significantly younger and including more male participants (table 1). Regarding subgroups of disorders, subgroup analyses revealed that gender and age differences could not be explained by the higher number of participants with substance use disorders among the HPG (online supplementary Stable 2). The APG significantly differed from the other two groups in higher verbal intelligence, school years and educational years (online supplementary Stable 3). Groups were also significantly

\section{Distribution of housing among participants}

Apartment Participant Group (APG)

Socio-therapeutic Facilities Participant Group (SPG)

Homeless Participant Group (HPG)

Number of patients

0

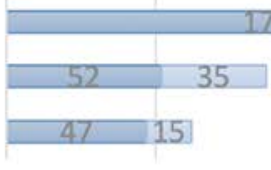

$50 \quad 100$

$\square$ male $\square$ female 
Table 1 Demographic and clinical characteristics for housing types

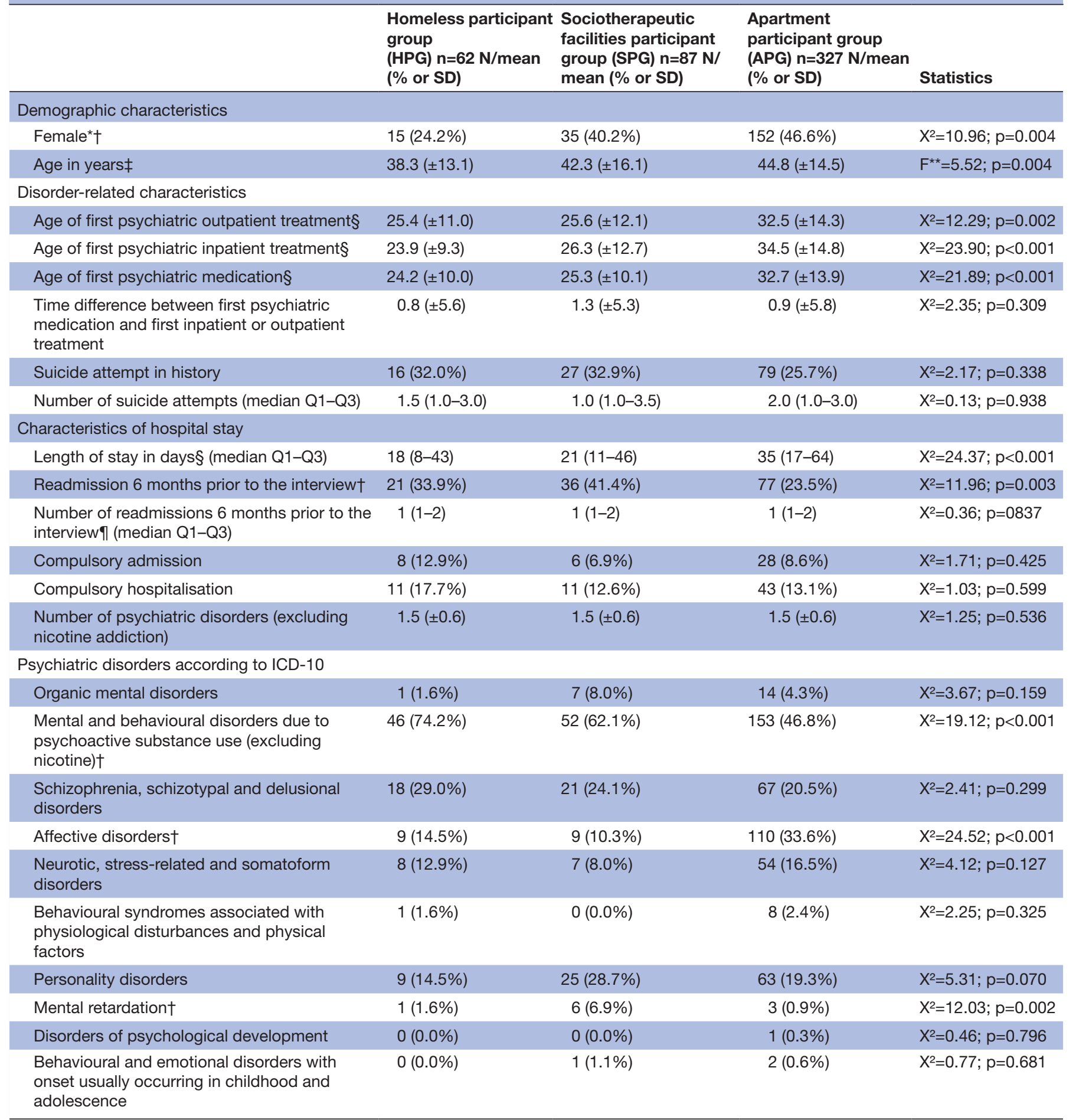

*One transgender person in APG.

†Significant group difference.

‡Significant group difference between APG and HPG after using Scheffe's method.

$\S$ Significant group difference after Mann-Whitney test and after adjusted alpha level by Bonferroni's method= $\alpha / 3$ ( $p$ level $=0.016)$ between the HPG and $A P G$ and SPG and APG, no significant group difference between HPG and SPG.

ISignificant group difference after Mann-Whitney test and after adjusted alpha level by Bonferroni's method= $\alpha / 3$ ( $p$ level=0.016) between SPG and APG.

${ }^{*}$ Analysis of variance.

different in distribution of school diploma and marital status, but not regarding country of origin or migration background (online supplementary Stable 3).
We observed significant group differences regarding the distribution of substance use disorders (highest in the HPG with $74.2 \%$ ), affective disorder (highest in the 
Table 2 Service use data for the three different housing groups

\begin{tabular}{|c|c|c|c|c|}
\hline & $\begin{array}{l}\text { Homeless } \\
\text { participant group } \\
\mathrm{n}=62 \\
\mathrm{~N}(\%)\end{array}$ & $\begin{array}{l}\text { Sociotherapeutic } \\
\text { facilities participant } \\
\text { group (SPG) } n=87 \\
N(\%)\end{array}$ & $\begin{array}{l}\text { Apartment } \\
\text { participant group } \\
n=327 \\
N(\%)\end{array}$ & Statistics \\
\hline Legal guardianship* & $23(37.1 \%)$ & $3(37.2 \%)$ & $58(17.8 \%)$ & $X^{2}=21.04 ; p<0.001$ \\
\hline Soup kitchen* & $17(27.4 \%)$ & $17(20.0 \%)$ & $12(3.7 \%)$ & $X^{2}=45.72 ; p<0.001$ \\
\hline Berlin Crisis Service & $4(6.5 \%)$ & $6(7.1 \%)$ & $27(8.3 \%)$ & $X^{2}=0.34 ; p=0.846$ \\
\hline Drug counselling service* & $17(27.4 \%)$ & $19(22.4 \%)$ & $44(13.5 \%)$ & $X^{2}=9.28 ; p=0.010$ \\
\hline Antipsychiatric crisis centre ('Weglaufhaus') & $0(0.0 \%)$ & $0(0.0 \%)$ & $1(0.3 \%)$ & $X^{2}=0.45 ; p=0.797$ \\
\hline Day care centre & $1(1.6 \%)$ & $2(2.4 \%)$ & $9(2.8 \%)$ & $X^{2}=0.30 ; p=0.862$ \\
\hline Faith-based supports & $4(6.5 \%)$ & $1(1.2 \%)$ & $6(1.8 \%)$ & $X^{2}=5.46 ; p=0.065$ \\
\hline $\begin{array}{l}\text { Individual supported living ('Betreutes } \\
\text { Einzelwohnen')* }\end{array}$ & $1(1.6 \%)$ & $29(34.1 \%) \dagger$ & $9(2.8 \%)$ & $X^{2}=91.52 ; p<0.001$ \\
\hline Psychosocial care* & $9(14.5 \%)$ & $15(17.6 \%)$ & $19(5.8 \%)$ & $X^{2}=13.85 ; p=0.001$ \\
\hline
\end{tabular}

*Significant group difference.

†High rate of individual supported living in the SPG group probably explained due to difficulties in differentiation between different forms of supported living.

APG with 33.6\%) and mental retardation (highest in the SPG with $6.9 \%$; table 1). Multinomial logistic regression of social and clinical factors associated with the current housing type revealed no school diploma as a significant predictor for being homeless; a diagnosis of a substance use disorder lost initial significance after correcting for multiple testing (online supplementary Stable 4). Being without a partner and having no school diploma or a diploma for handicapped children were significant predictors for living in a sociotherapeutic facility (online supplementary Stable 4).

\section{Healthcare utilisation}

Participants in the HPG did not use social and healthcare services 6 months prior to admission significantly less frequently and with even higher rates they used legal guardianship, soup kitchens, an emergency bus for cold weather, drug counselling services and psychosocial care (table 2). Participants from the HPG and SPG were significantly younger compared with the APG when first in contact with the psychiatric healthcare system (table 1). Regarding hospital use, participants in the APG had a significant longer LoS than participants from the HPG and SPG (table 1).

In the multiple linear regression model, a higher log of LoS was significantly associated with being diagnosed with an affective disorder, schizophrenia, schizotypal or delusional disorder or a neurotic, stress-related or somatoform disorder. The diagnosis of a substance use disorder (excluding nicotine) was significantly associated with a shorter LoS. Being homeless or living in a sociotherapeutic facility was also significantly associated with a shorter LoS (table 3).

Being readmitted was significantly predicted by being diagnosed with a substance use disorder, schizophrenia, schizotypal or delusional disorders or a personality disorder and living in a sociotherapeutic facility (table 3).

Disorders of psychological development and behavioural and emotional disorders with onset usually occurring in childhood and adolescence were excluded due to a small sample size.

Being readmitted was significantly associated with being diagnosed with a substance use disorder, schizophrenia, schizotypal or delusional disorders or a personality disorder and living in a sociotherapeutic facility (significance of the model: $\mathrm{p}<0.001$ ).

When entered into the equation in the first step, sociodemographic variables accounted for $2.4 \%$ of the variance of LoS. Introducing clinical indicators of psychiatric diagnoses explained an additional 22.4\%. Adding the housing status (being homeless and sociotherapeutic facilities, own apartment as reference) explained an additional $2.7 \%$ of the variance of LoS. In the full model, a higher LoS was significantly associated with being diagnosed with an affective disorder, schizophrenia, schizotypal or delusional disorder or a neurotic, stress-related or somatoform disorder. The diagnosis of a substance use disorder (excluding nicotine) was significantly associated with a shorter LoS. Being homeless or living in a sociotherapeutic facility was significantly associated with a shorter LoS. 


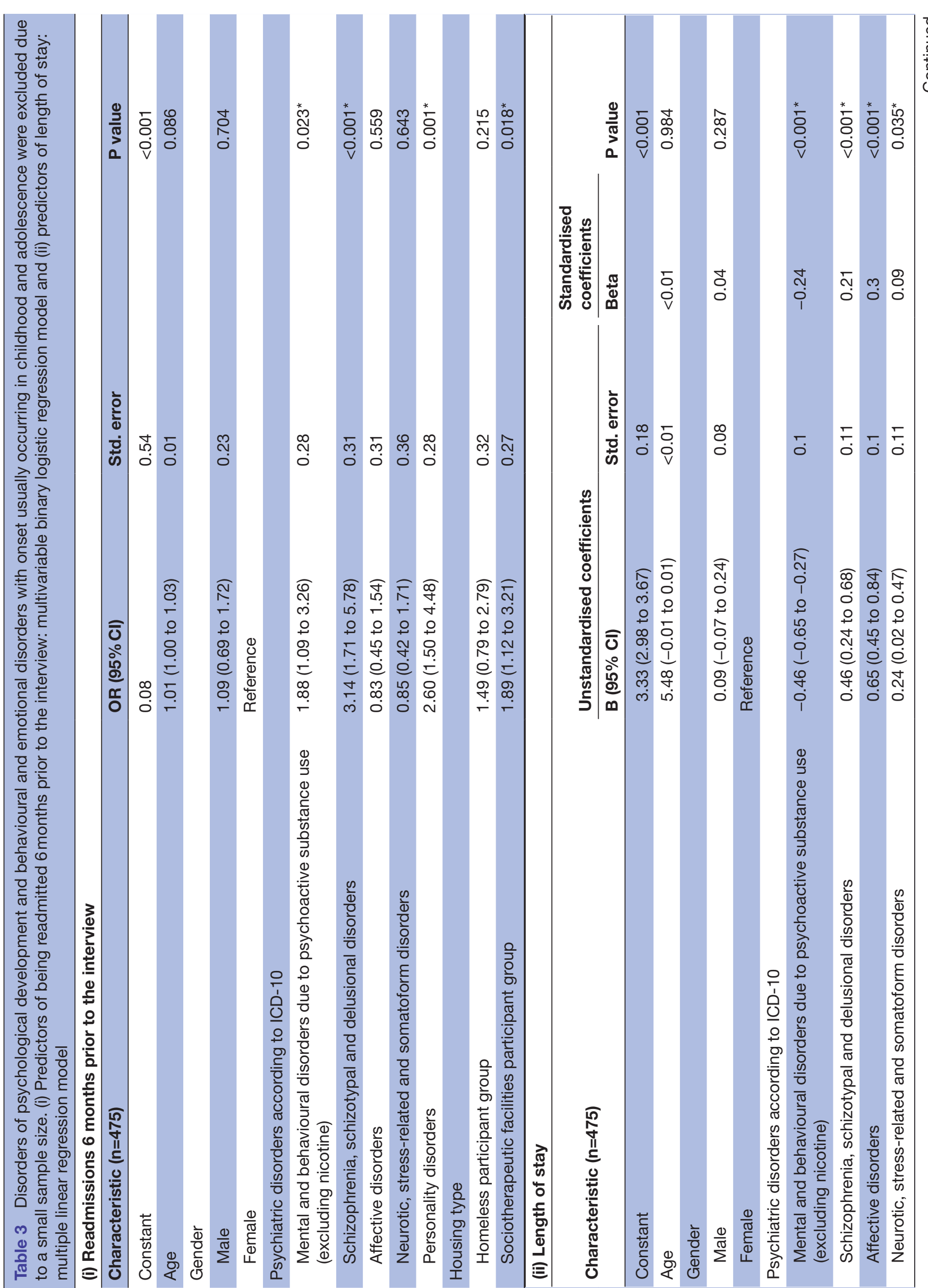

通 


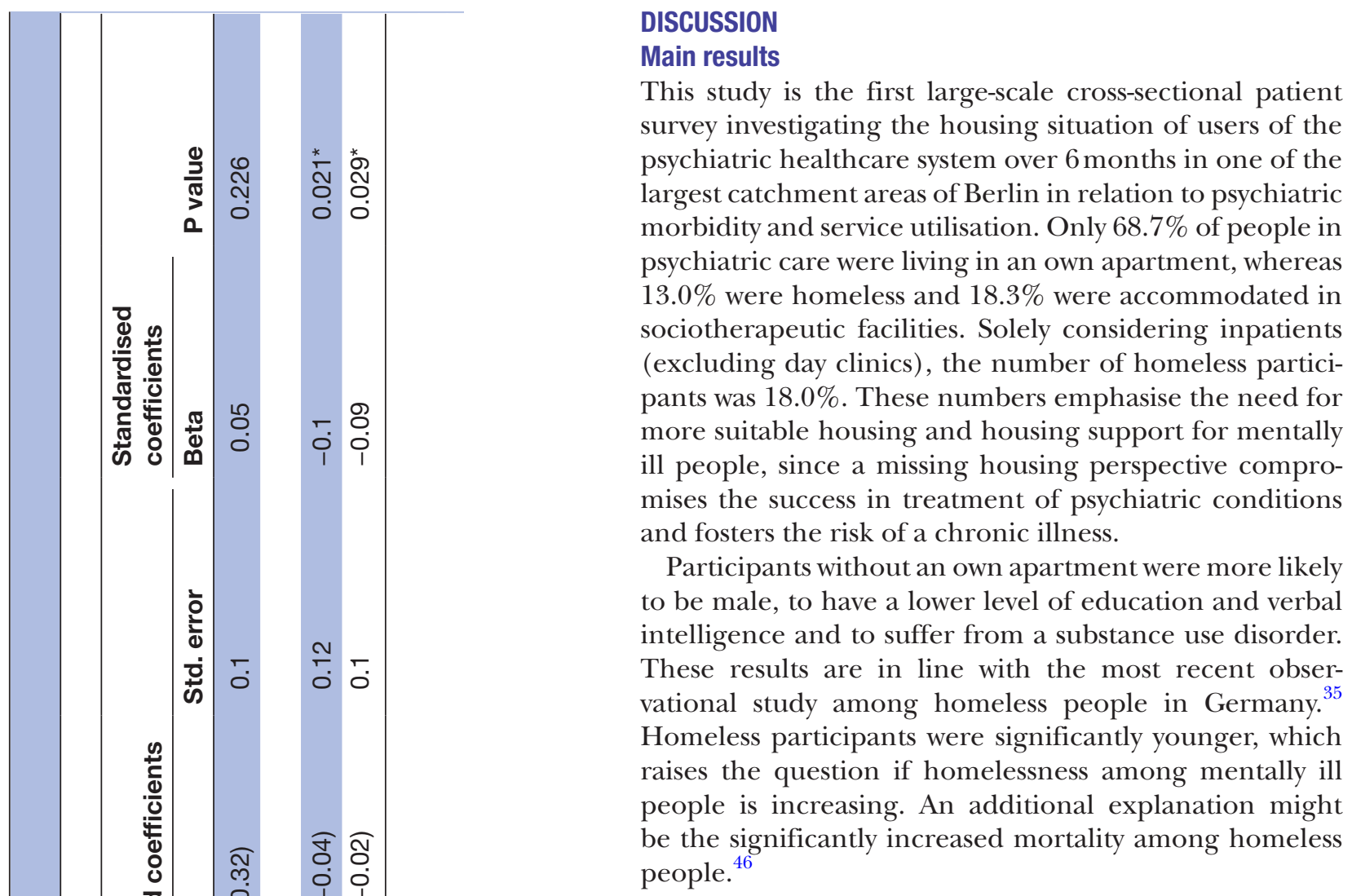

\section{Education and verbal intelligence}

Participants without an own apartment had a significantly lower level of education and verbal intelligence: $25.0 \%$ of homeless participants had no school diploma. Additionally, having no school diploma was a significant predictor for being homeless or living in a sociotherapeutic facility. A low level of education or level of intelligence increases the risk for homelessness, since it might lead to fewer resources to attend social matters. Additionally, a higher vulnerability for a psychiatric illness adds to the risk of marginalisation.

\section{Housing and correlation to clinical characteristics}

Being diagnosed with a substance use disorder was a significant predictor for being homeless, which is in accordance with other studies on homeless populations. ${ }^{22} 47$ According to a recent meta-analysis, homeless people in Germany present with a 1.5 times higher rate of alcohol dependency than homeless people in other western countries and a 21 times higher prevalence of substancerelated disorders than the general German population $(2.9 \%) .{ }^{22}$ One explanation is a support system, which is often based on abstinence in contrast to evidence-based housing first (HF) concepts ${ }^{48}$ making it difficult for those particularly at risk to access the mental healthcare system (eg, people with missing health insurance, experienced stigma or negative attitudes towards the mental health system). Additionally, the availability and price regulation of drugs in Germany result in comparatively low alcohol prices. These structural barriers negatively add to the individual risk of being drawn towards substance use as 
a major coping strategy among those who are marginalised. ${ }^{49}$ HF provides homeless individuals with mental illness immediate access to permanent housing as well as services and supports that are flexible and consumer driven. ${ }^{48}$ Research on HF has documented improved residential stability, community integration and high levels of client satisfaction. ${ }^{23}$

Homeless participants were significantly younger while first in contact with the psychiatric healthcare system. Also, the diagnostic subgroup of homeless participants with substance use disorders was significantly younger when being hospitalised or in psychiatric outpatient treatment for the first time compared with stably housed participants. A poorer social environment and possibly early trauma experience ${ }^{50}$ might lead to an earlier development of coping mechanisms like substance use clearing the way for the consolidation of a substance user disorder or other mental illness. In turn, this development sustains a poor social development often mirrored in a higher risk of being homeless. Our data underline the association between an early onset of disease and a poorer prognosis in terms of social conditions, such as housing later in life. A later onset of disease might go along with a better chance to build up a psychosocial support system, since onset of disease often concurs within vulnerable phases of life (eg, finding a vocational path, separation from home).

\section{Housing and healthcare utilisation}

LoS was significantly shorter in homeless participants compared with the APG, which is in contrast to international studies. ${ }^{31} 51$ In subgroup analyses for the biggest diagnostic subgroups, in the group of substance user disorder participants homeless participants stayed as long as participants in an own apartment. We also found no significant difference in the subgroup of psychotic disorders in LoS and readmissions. A multiple linear regression revealed a strong association of LoS and psychiatric diagnoses; housing type only explained for an additional $2.7 \%$ of variance of LoS. In a prospective cohort study among psychiatric inpatients among different European countries, homelessness predicted LoS in opposite directions in different countries: compared with other patients, homeless patients stayed longer in hospitals in Belgium, UK and Italy, but shorter in Germany. ${ }^{51}$ Homeless people might not have the resources and support to seek help and benefit from hospital-based care, especially if barriers are high. If taken into account that non-participants stayed on average 10 versus 28 days in hospital care with rates of involuntary admissions almost twice as high compared with participants, one hypothesis suggests that more severely ill people will be treated initially involuntarily but will be discharged as soon as the legal basis for a compulsory hospitalisation has run out. Unwillingness to continue the hospital treatment due to other priorities like housing matters or negative experiences in the past might lead to an early end of inpatient treatment. Additionally, being readmitted was not significantly associated with being homeless, but with living in a sociotherapeutic facility. Whereas homeless people might not be able the seek help accordingly, especially in a rather fragmented service system, people in sociotherapeutic facilities benefit from the support of their caregivers. Concerning ambulatory service use, we did not find a lower utilisation of ambulatory and housing specific services in unstably housed participants.

\section{Limitations}

Our data cannot be generalised for other districts or rural areas, since studies have shown that the risk for serious mental illness is generally higher in cities compared with rural areas. ${ }^{3839}$ Outpatients were not included limiting the representativeness to people with mental illness without a history of hospitalisation. Additionally, the hospital's catchment is characterised by its relatively low living standards and high rates of migrants especially from other European countries. Nevertheless, we detected no significant group difference in type of housing and migration background or country of origin. We conducted our interviews during summer time, which might have changed the ratio of homeless patients in our clinic. Furthermore, due to the complexity of the social and healthcare system in Germany, there might be a bias in self-report of service utilisation (eg, high case management in sociotherapeutic facilities).

\section{CONCLUSION}

The prevalence among people in acute psychiatric care living in instable housing including street homelessness is concerning. Only $68.7 \%$ were living in an own apartment. Participants without an own apartment were more likely to be male and younger, to have a lower level of education and verbal intelligence and suffer from a substance use disorder. Their circumstances in life especially the high rate of substance use demand a shift in the model of care in the form of specific outreach capacities, quality addiction treatment and better integration with social services. ${ }^{23}$ In order to address these demands, more evidence is needed informing healthcare system development including a system evaluation of the current state. Specialised outreach services should be considered to better integrate substance use, mental health and physical healthcare with social services.

\section{Author affiliations}

${ }^{1}$ Department of Psychiatry and Psychotherapy, Charité - Universitätsmedizin Berlin, corporate member of Freie Universität Berlin, Humboldt-Universität zu Berlin, and

Berlin Institute of Health, Berlin, Germany

${ }^{2}$ Department of Psychiatry and Psychotherapy, Psychiatrische Universitätsklinik der Charité im St. Hedwig-Krankenhaus, Berlin, Germany

${ }^{3}$ Department of Psychiatry and Psychotherapy, Universität Zürich, Zurich, Switzerland

${ }^{4}$ Department of Psychiatry, The University of British Columbia, Vancouver, British Columbia, Canada

${ }^{5}$ Department of Psychiatry and Psychotherapy, Klinikum rechts der Isar der Technischen Universität München, München, Germany 
Acknowledgements The authors want to thank all patients for their participation and talking freely about their challenges and sharing their experiences. They also like to thank patient advisers for reviewing the interview form. They thank Pimrapat Gebert from the Institute of Biometry and Clinical Epidemiology Charité for her advice.

Contributions SS and SG were responsible for drafting and revising the original study protocol; they were the chief investigators and had overall responsibility for management of the trial; they delivered the training to the interviewers. SH, JZ, US, $A B, T M, M S-0$ and FB revised the original study protocol. FB and MS- 0 provided additional clinical supervision. SH, JZ, US and AB collected the data. SS and SH wrote the analysis plan and cleaned and analysed the data under supervision from SG, WR, MRK and JB. SS, SG and JZ wrote the first draft of the report and revised subsequent draft. All authors contributed to and approved the final report. SS, FB, TM and MS-0 performed the revision.

Funding The authors have not declared a specific grant for this research from any funding agency in the public, commercial or not-for-profit sectors.

Competing interests None declared.

Patient consent for publication Not required

Ethical approval The local ethics committee of the Charité - Universitätsmedizin Berlin approved the study (Number: EA1/291/15).

Provenance and peer review Not commissioned; externally peer reviewed.

Data availability statement Data can not made available because of patient data privacy.

Open access This is an open access article distributed in accordance with the Creative Commons Attribution Non Commercial (CC BY-NC 4.0) license, which permits others to distribute, remix, adapt, build upon this work non-commercially, and license their derivative works on different terms, provided the original work is properly cited, appropriate credit is given, any changes made indicated, and the use is non-commercial. See: http://creativecommons.org/licenses/by-nc/4.0/.

\section{ORCID iD}

Stefanie Schreiter http://orcid.org/0000-0001-9598-0029

\section{REFERENCES}

1 Vetrano DL, Tosato M, Colloca G, et al. SHELTER study. polypharmacy Nurs home Resid with sev Cogn impair results from shelter study. Alzheimers Dement; 10.

2 Krausz M, Strehlau V, Schütz C, et al. Frühe Traumatisierung bei Menschen in Wohnungsligkeit und Armut. Trauma Gewalt 2013:290-300.

3 Vila-Rodriguez F, Panenka WJ, Lang DJ, et al. The hotel study: multimorbidity in a community sample living in marginal housing. Am $J$ Psychiatry 2013:170:1413-22.

4 Noël F, Moniruzzaman A, Somers J, et al. A longitudinal study of suicidal ideation among homeless, mentally ill individuals. Soc Psychiatry Psychiatr Epidemiol 2016;51:107-14.

5 Prigerson HG, Desai RA, Liu-Mares W, et al. Suicidal ideation and suicide attempts in homeless mentally ill persons: age-specific risks of substance abuse. Soc Psychiatry Psychiatr Epidemiol 2003;38:213-9.

6 Babidge NC, Buhrich N, Butler T. Mortality among homeless people with schizophrenia in Sydney, Australia: a 10-year follow-up. Acta Psychiatr Scand 2001;103:105-10.

7 Barrow SM, Herman DB, Córdova P, et al. Mortality among homeless shelter residents in New York City. Am J Public Health 1999;89:529-34.

8 Jones AA, Vila-Rodriguez F, Leonova O, et al. Mortality from treatable illnesses in marginally housed adults: a prospective cohort study. BMJ Open 2015;5:e008876.

9 Nikoo N, Motamed M, Nikoo MA, et al. Chronic physical health conditions among homeless. J Health Dispar Res Pract 2015:8:81-97.

10 Fichter M, Quadflieg N, Cuntz U. Prävalenz körperlicher und seelischer Erkrankungen. Dtsch Arzteb/ 2000;97:1148-54.

11 Völlm B, Becker H, Kunstmann W. Pärvalenz körperlicher Erkrankungen, Gesundheitsverhalten und Nutzung des Gesundheitssystems bei alleinstehenden wohnungslosen Männern: eine Querschnittsuntersuchung. Sozial- und Präventivmedizin 2004;49:42-50.

12 Fazel S, Grann M. The population impact of severe mental illness on violent crime. Am J Psychiatry 2006;163:1397-403.
13 Brennan PA, Mednick SA, Hodgins S. Major mental disorders and criminal violence in a Danish birth cohort. Arch Gen Psychiatry 2000;57:494-500.

14 Gelberg L, Linn LS, Leake BD, et al. Mental health, alcohol and drug use, and criminal history among homeless adults. Am J Psychiatry 1988;145:191-6.

15 Torchalla I, Linden IA, Strehlau V, et al. "Like a lots happened with my whole childhood": violence, trauma, and addiction in pregnant and postpartum women from Vancouver's Downtown Eastside. Harm Reduct J 2015;12:34.

16 Edalati H, Krausz M, Schütz CG. Childhood maltreatment and Revictimization in a homeless population. J Interpers Violence 2016;31:2492-512.

17 Walsh E, Moran P, Scott C, et al. Prevalence of violent victimisation in severe mental illness. Br J Psychiatry 2003;183:233-8.

18 Stergiopoulos V, Cusi A, Bekele T, et al. Neurocognitive impairment in a large sample of homeless adults with mental illness. Acta Psychiatr Scand 2015;131:256-68.

19 Cooper E, Knott L, Schaak G. Priced out in 2014 - the housing crisis for people with disabilities, 2015: 1-57. http://www.tacinc.org/media/ 52012/Priced Out in 2014.pdf

20 O'Hara A, Cooper E. Priced out in 2002. 2003.

21 PRESSEMITTEILUNG. Bundesarbeitsgemeinschaft Wohnungs/osenhilfe e V, 2019. Available: http://www.bagw.de/de/ themen/zahl_der_wohnungslosen/index.html [Accessed 2019-1005].

22 Schreiter S, Bermpohl F, Krausz M, et al. The prevalence of mental illness in homeless people in Germany. Dtsch Arztebl Int 2017;114:665-72.

23 Gühne U, Weinmann S, Riedel-heller S, et al. Kurzfassung Der S3-Leitlinie Psychosoziale Therapien bei schweren psychischen Erkrankungen 2018;2019.

24 McCormick B, White J. Hospital care and costs for homeless people. Clin Med 2016;16:506-10.

25 Hwang SW, Chambers C, Chiu S, et al. A comprehensive assessment of health care utilization among homeless adults under a system of universal health insurance. Am J Public Health 2013;103(Suppl 2):S294-301.

26 Hwang SW, Weaver J, Aubry T, et al. Hospital costs and length of stay among homeless patients admitted to medical, surgical, and psychiatric services. Med Care 2011;49:350-4.

27 Verlinde E, Verdée T, Van de Walle M, et al. Unique health care utilization patterns in a homeless population in Ghent. BMC Health Serv Res 2010;10:242.

28 Kushel MB, Vittinghoff E, Haas JS. Factors associated with the health care utilization of homeless persons. JAMA 2001;285.

29 Hwang SW. Homelessness and health. CMAJ 2001;164:229-33.

30 Gelberg L, Gallagher TC, Andersen RM, et al. Competing priorities as a barrier to medical care among homeless adults in Los Angeles. Am J Public Health 1997;87:217-20.

31 Salit SA, Kuhn EM, Hartz AJ, et al. Hospitalization costs associated with homelessness in New York City. $N$ Engl J Med 1998;338:1734-40

32 Meller I, Fichter M, Quadflieg N, et al. Die Inanspruchnahme medizinischer und psychosozialer Dienste durch psychisch erkrankte Obdachlose: Ergebnisse einer epidemiologischen studie. Nervenarzt 2000;71:543.

33 Dufeu P, Podschus J, Schmidt LG. Alkoholabhängigkeit bei männlichen Wohnungslosen. Nervenarzt 1996;67:930-4.

34 Salize HJ, Horst A, Dillmann-Lange C, et al. Needs for mental health care and service provision in single homeless people. Soc Psychiatry Psychiatr Epidemiol 2001;36:207-16.

35 Bäuml J, Brönner M, Baur B, et al. Die SEEWOLF-Studie Seelische Erkrankungsrate in den Einrichtungen Der Wohnungslosenhilfe Im Großraum München 2017.

36 Wessel T, Pörksen N, Zechert C. Wohnungslose Patienten in Der Psychiatrischen Klinik. Psychiatr Prax 1997;24:167-71.

37 Nordentoft M, Knudsen HC, Schulsinger F. Housing conditions and residential needs of psychiatric patients in Copenhagen. Acta Psychiatr Scand 1992;85:385-9.

38 Gruebner O, Rapp MA, Adli M, et al. Cities and mental health. Dtsch Arztebl Int 2017;114:121-7.

39 Rapp MA, Kluge U, Penka S, et al. When local poverty is more important than your income: mental health in minorities in inner cities. World Psychiatry 2015;14:249-50.

40 AfS Berlin-Brandenburg. Statistischer Bericht A / 5 - hj 2/14. Einwohnerinnen und Einwohner im Land Berlin am 31, 2015.

41 Senatsverwaltung für Gesundheit und Soziales Berlin. Krankenhaushäufigkeit in Berlin 1998 - 2015 nach Fachabteilungen, 2015. 
42 Graubner B. ICD-10-GM (internationale statistische Klassifikationen Der Krankheiten und verwandter Gesundheitsprobleme. Deutscher Ärzteverlag, 2013.

43 Lehrl S. Mehrfachwahl-Wortschatz-Intelligenztest: MWT-B. Balingen: Spitta, 2005

44 Kay SR, Fiszbein A, Opler LA. The positive and negative syndrome scale (PANSS) for schizophrenia. Schizophr Bull 1987;13:261-76.

45 IBM CR. IBM SPSS statistics for windows, version 19.0. Armonk, NY: IBM Corp, 2010

46 Aldridge RW, Story A, Hwang SW, et al. Morbidity and mortality in homeless individuals, prisoners, sex workers, and individuals with substance use disorders in high-income countries: a systematic review and meta-analysis. Lancet 2018;391:241-50.

47 Fazel S, Khosla V, Doll H, et al. The prevalence of mental disorders among the homeless in Western countries: systematic review and meta-regression analysis. PLoS Med 2008;5:e225-81.
48 Patterson M, Moniruzzaman A, Palepu A, et al. Housing first improves subjective quality of life among homeless adults with mental illness: 12-month findings from a randomized controlled trial in Vancouver, British Columbia. Soc Psychiatry Psychiatr Epidemiol 2013;48:1245-59.

49 Khantzian EJ. Self-regulation and self-medication factors in alcoholism and the addictions. similarities and differences. Recent Dev Alcohol 1990;8:255-71.

50 Sundin EC, Baguley T. Prevalence of childhood abuse among people who are homeless in Western countries: a systematic review and meta-analysis. Soc Psychiatry Psychiatr Epidemiol 2015:50:183-94.

51 Dimitri G, Giacco D, Bauer M, et al. Predictors of length of stay in psychiatric inpatient units: does their effect vary across countries? Eur Psychiatry 2018;48:6-12. 